Archive for

Organic Chemistry

Arkivoc 2017, part iii, 130-139

\title{
1,2,5-Thiadiazolo[3,4-b]pyrazine-5,6-dicarbonitrile and derived porphyrazines: synthesis and electrochemical study
}

Maksim S. Mikhailov, Mahmoud Hamdoush, Mikhail K. Islyaikin, Oskar I. Koifman, and Pavel A. Stuzhin*

Research Institute of Macroheterocycles, Ivanovo State University of Chemistry and Technology, RF-153460 Ivanovo, Russia

E-mail: stuzhin@isuct.ru

Dedicated to Professor Oleg Alekseevich Rakitin on the occasion of his 65th birthday

Received 03-19-2017

Accepted 04-28-2017

Published on line 05-14-2014

\section{Abstract}

1,2,5-Thiadiazolo[3,4-b]pyrazine-5,6-dicarbonitrile, obtained by reaction of 5,6-diaminopyrazine-2,3-dicarbonitrile with $\mathrm{SOCl}_{2}$, exhibits strongly electron-deficient properties and easily forms reduced species (the reduction potentials -0.01 and $-1.02 \mathrm{~V}$ in $\mathrm{MeCN} v \mathrm{Ag} / \mathrm{AgCl}$ ). Template cyclotetramerization in the presence of Mg butoxide in $n$-butanol and with indium(III) chloride in 1,2,4-trichlorobenzene affords the corresponding complexes of tetrakis(1,2,5-thiadiazolo[3',4':5,6]pyrazino) $[2,3-b, g, l, q]$ porphyrazine, [(TSN $\left.\left.{ }_{2} \mathrm{Pyz}_{2} \mathrm{PA}\right) \mathrm{M}\right]$ (M = $\left.\mathrm{Mg}\left(\mathrm{H}_{2} \mathrm{O}\right), \operatorname{lnCl}\right)$. The $\mathrm{Mg}(\mathrm{II})$ complex is characterized by a Q-band at 657 and a Soret band at $370 \mathrm{~nm}$ (in DMSO) and shows three reduction processes at $-0.38,-0.83$ and $-1.21 \mathrm{~V}$ vs $\mathrm{Ag} / \mathrm{AgCl}$ in DMSO.

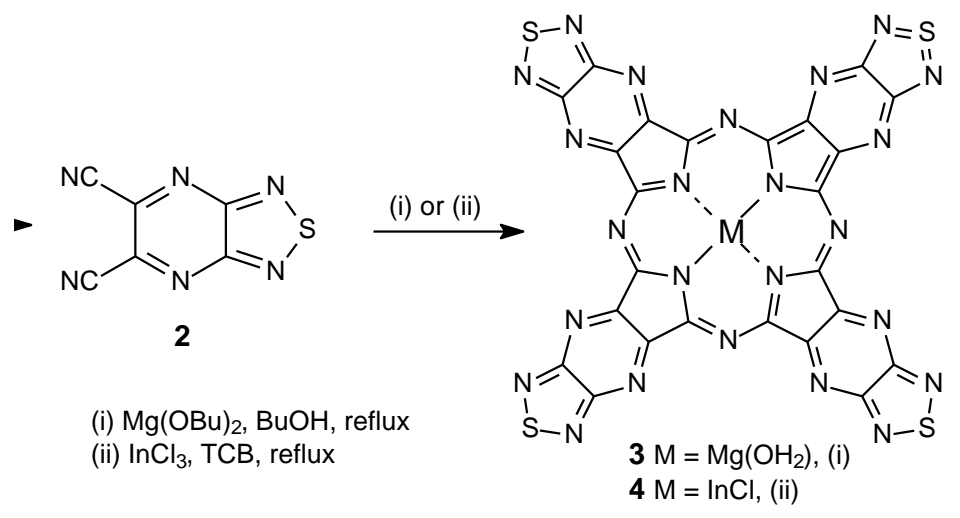

Keywords: 1,2,5-Thiadiazolo[3.4-b]pyrazine-2,3-dicarbonitrile, porphyrazines, magnesium(II), indium(III) complexes, UV-vis spectra, electrochemistry 


\section{Introduction}

Heterocyclic phthalocyanine analogues - porphyrazines (PA) bearing annulated aromatic heterocycles instead of benzene rings - are widely investigated in different areas of practical application. ${ }^{1}$ Porphyrazines with four fused 1,2,5-chalcogenadiazole rings, $\left[T\left(X N_{2}\right) P A M\right](X=S$, Se, Te) exhibit remarkable electron-deficient properties $^{2,3}$ and for tetra(1,2,5-thiadiazolo)porphyrazine and its metal complexes [T(SN $\left.\left.)_{2}\right) \mathrm{PAM}\right](\mathrm{M}=2 \mathrm{H}, \mathrm{Zn}$, $\mathrm{Fe}, \mathrm{V}=\mathrm{O}$ ) their potential for application in organic electronics as $n$-type conducting materials has been demonstrated. ${ }^{4-7}$ In recent years increasing attention has been paid to octasubstituted tetrapyrazinoporphyrazines (TPyzPA) bearing various types of substituent on the pyrazine rings, such as alkyl, alkenyl, aryl, hetaryl, alkoxy, dialkylamino and alkylthio groups. ${ }^{8}$ Peripheral substituents in TPyzPA macrocycle allow fine-tuning its electronic, spectral and coordination properties which is quite important for the application of TPyzPAs and their complexes in different fields (as singlet oxygen sensitizers, fluorescence sensors, catalysts, materials for non-linear optics and organic electronics). ${ }^{8}$ Unlike phthalocyanines, which are commonly used as $p$-semiconducting materials, complexes of TpyzPA, due to the presence of $\pi$-deficient pyrazine fragments, exhibit $n$-semiconducting properties. ${ }^{9}$ The $\pi$-electron-deficiency of a TPyzPA macrocycle can be increased by introduction of electron-withdrawing substituents on the pyrazine rings, e.g. chlorine atoms. ${ }^{10}$ TPyzPAs bearing eight $\alpha$-pyridyl groups also exhibit remarkable electron-deficient properties which can be further increased by quaternization of the pyridine rings or their involvement in peripheral coordination of $\mathrm{Pd}(\mathrm{II})$ or $\mathrm{Pt}(\mathrm{II}) .{ }^{11}$ Since chlorine atoms exhibit a $+M(+C)$ effect and $\alpha$-pyridyl groups, being noncoplanar with the TPyzPA macrocycle, are only partly involved in conjugation, the electron-acceptor properties of these substituents are mainly due to their -l electronic effects. Direct fusion of heterocycles to pyrazine rings can more strongly affect the $\pi$-acceptor properties of a TPyzPA macrocycle. So far, reports on such $\pi$ extended TPyzPAs include macrocycles with fused pyrrole, ${ }^{12}$ indole, $^{13}$ thianaphthene, ${ }^{14,15} 1,2,4$-triazole, ${ }^{16}$ and pyrazine $^{17-19}$ fragments. The low-symmetry porphyrazines combining three pyrazine and one 1,2,5chalcogenadiazole ring fused to different pyrrole rings have been recently reported. ${ }^{20}$

We have prepared the first TPyzPA with annulated 1,2,5-thiadiazole rings, and report here the characterization of the dinitrile precursor 1,2,5-thiadiazolo[3,4-b]pyrazine-5,6-dicarbonitrile (2) and the synthesis of its cyclotetramerization products, the $\mathrm{Mg}(\mathrm{II})$ and $\ln (\mathrm{III})$ complexes of tetrakis(1,2,5thiadiazolo[3,4:5,6]pyrazino)porphyrazine, $\left[\mathrm{T}\left(\mathrm{SN}_{2} \mathrm{Pyz}\right) \mathrm{PAM}\right](\mathrm{M}=\mathrm{Mg}(3), \ln (\mathrm{Cl})(4))$.

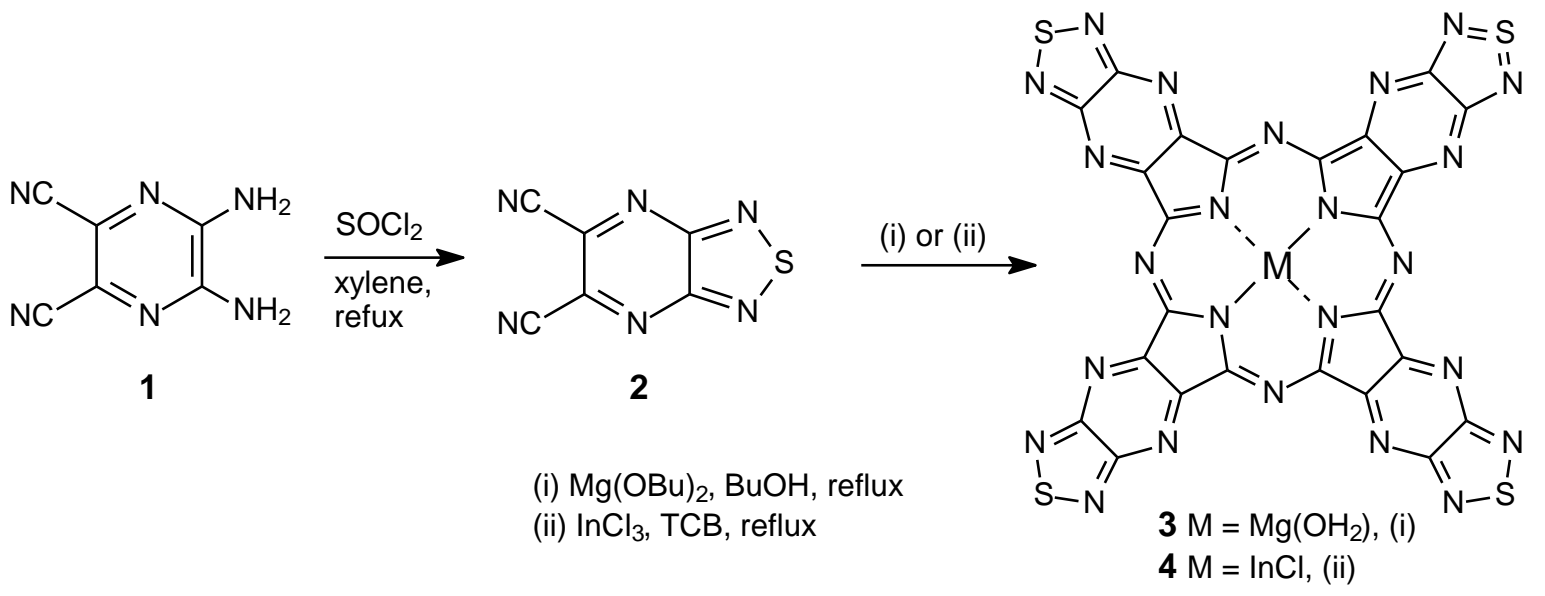

Scheme 1. Synthesis of tetrakis(1,2,5-thiadiazolo[3,4:5,6]pyrazino)porphyrazines 3 and $\mathbf{4}$. 


\section{Results and Discussion}

\section{Dinitrile precursor 2}

1,2,5-Thiadiazolo[3,4-b]pyrazine-5,6-dicarbonitrile, $\left(\mathrm{SN}_{2}\right) \mathrm{Pyz}(\mathrm{CN})_{2}(2)$, was prepared by condensation of 2,3diaminopyrazine-5,6-dicarbonitrile (1) with excess of thionyl chloride upon reflux closely following the procedure suggested by Tong. ${ }^{21}$ The crude product can be purified by vacuum sublimation at $150-200{ }^{\circ} \mathrm{C}$ to give light yellow crystals. In the IR spectrum of the dinitrile $\mathbf{2}$ are seen the low intensity stretching $\mathrm{C} \equiv \mathrm{N}$ vibration at $2235 \mathrm{~cm}^{-1}$ and a very strong band at $1251 \mathrm{~cm}^{-1}$ (Figure 1). The IR spectrum calculated theoretically (DFT/B3LYP/6-311+G(d)) allows assignment of this intense band to a skeletal vibration of the pyrazine ring (calc. at $1260 \mathrm{~cm}^{-1}$ ) with large contribution of the $\mathrm{C} \cdots \mathrm{C}$ bond stretching, while a weaker band at $1365 \mathrm{~cm}^{-1}$ is due to $\mathrm{C} \cdots \mathrm{C}$ and $\mathrm{C} \cdots \mathrm{N}$ bond stretching (calc. at $1482 \mathrm{~cm}^{-1}$ ). The vibrations with stretching of S-N bonds are calculated at 832,865 and $932 \mathrm{~cm}^{-1}$ and the most intense band observed at $902 \mathrm{~cm}^{-1}$ is due to asymmetrical vibration. The calculations also indicate low intensity for the $\mathrm{C} \equiv \mathrm{N}$ stretching modes and that the band observed at $1124 \mathrm{~cm}^{-1}$ corresponds to the asymmetrical stretching mode of the C-CN bonds (calc. at 1155 $\left.\mathrm{cm}^{-1}\right)$.

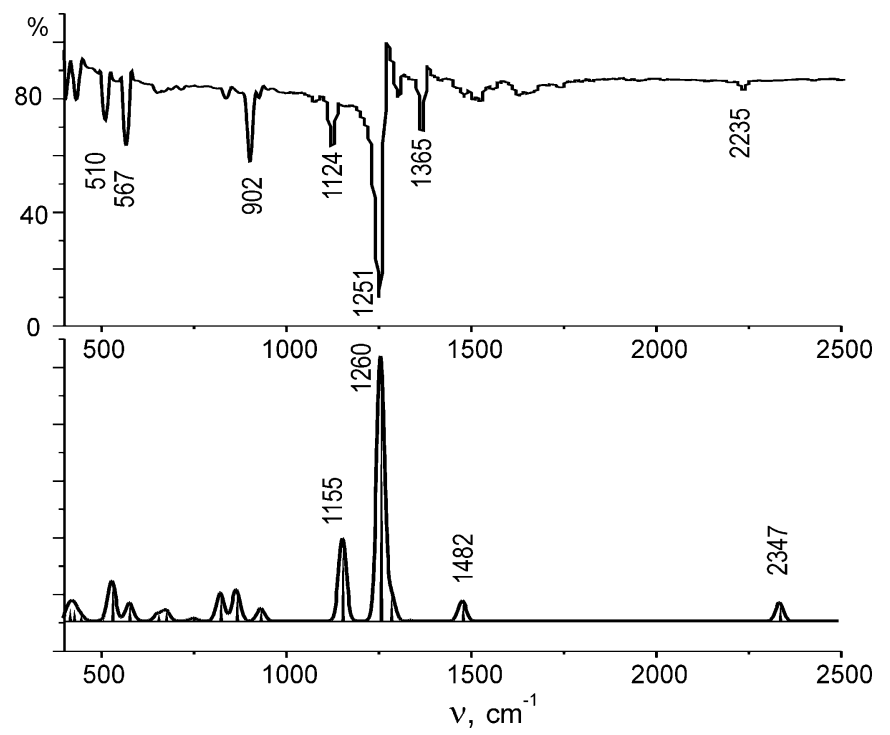

Figure 1. Experimental (top) and calculated (bottom) IR spectra of 1,2,5-thiadiazolo[3,4-b]pyrazine-5,6dicarbonitrile (2).

The LDI mass-spectrum of the dinitrile $\mathbf{2}$ which was obtained in the negative mode contains two peaks of almost equal intensity corresponding to the negative molecular ion $[\mathrm{M}]^{-}(\mathrm{m} / \mathrm{z}=188)$ and the desulfurated fragment $[\mathrm{M}-\mathrm{S}]^{-}(\mathrm{m} / \mathrm{z}=156)$ (see Suppl. Material). While solutions of the dinitrile 2 in $\mathrm{CH}_{2} \mathrm{Cl}_{2}$ and $\mathrm{MeCN}$ are colorless and stable, its dissolution in pyridine results in formation of a red-brown solution which is decolorized upon staying in the contact of oxygen.

The UV-VIS spectra of 2 in $\mathrm{CH}_{2} \mathrm{Cl}_{2}$ and MeCN have absorption band in UV region at 350 $\mathrm{nm}$ (see Figure 2a). The red-brown solution in pyridine is characterized by the presence of absorption bands with maxima 413, 547, 570 and $714 \mathrm{~nm}$ (see Figure 2b). Such spectral changes can be assigned to the reduction of the dinitrile occurring in pyridine as an electron-donor solvent. Indeed, according to theoretical TD DFT calculations the single electron reduction of the colorless dinitrile $\mathbf{2}$ should lead to appearance of the absorption band in the visible region at $671 \mathrm{~nm}$ in addition to the double band at 399 and $463 \mathrm{~nm}$ (Figure 2b'). 


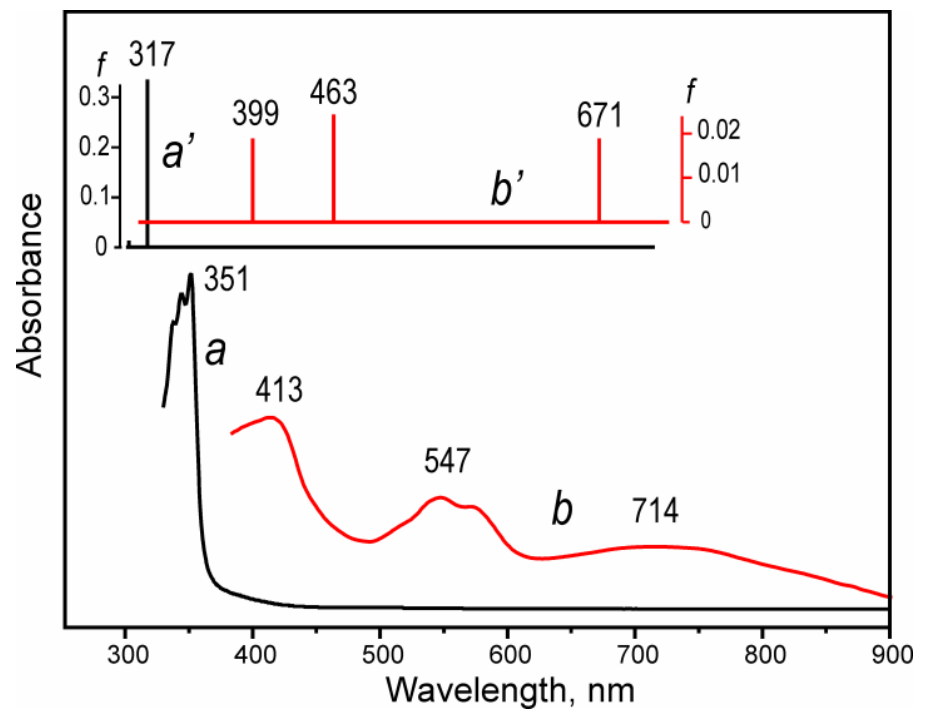

Figure 2. UV-VIS spectra of 1,2,5-thiadiazolo[3,4-b]pyrazine-5,6-dicarbonitrile (2) in $\mathrm{CH}_{2} \mathrm{Cl}_{2}$ (a) and in pyridine (b). Insert shows theoretical spectra for the dinitrile $\mathbf{2}\left(a^{\prime}\right)$ and its singly reduced form ( $\left.b^{\prime}\right)$.

It is noteworthy that one-electron electrochemical reduction of pyrazine-2,3-dicarbonitriles containing aryl groups in 5,6-positions, $(\operatorname{Ar})_{2} \mathrm{Pyz}(\mathrm{CN})_{2}(\mathrm{Ar}=$ phenyl $(\mathrm{Ph})$, 2-pyridyl $(\mathrm{Py})$, 2-thienyl $(\mathrm{Th}))$, which occurs in pyridine at $-0.9--1.0 \mathrm{~V}$ vs SCE leads to appearance of the broad band centered at $\sim 620 \mathrm{~nm} .^{22}$ In the case of 2,3-di-(2-pyridyl)quinoxaline-6,7-dicarbonitrile, $(\mathrm{Py})_{2}(\mathrm{PyzBz})(\mathrm{CN})_{2}$, the reduction in DMSO at $-0.88 \mathrm{~V}$ vs SCE leads to the colored product with maxima at 420,585, 641 and $700 \mathrm{~nm} .{ }^{23}$ We have studied electrochemical properties of the dinitrile 2, $\left(\mathrm{SN}_{2}\right) \mathrm{Pyz}(\mathrm{CN})_{2}$, and found that in $\mathrm{MeCN}$ two reversible reduction processes are observed at -0.01 and $-1.02 \mathrm{~V}$ vs $\mathrm{Ag} / \mathrm{AgCl}$ (see Figure 3) and in DMSO as an electron-donor solvent the first reduction is shifted to the positive region to $+0.08 \mathrm{~V}$ vs $\mathrm{Ag} / \mathrm{AgCl}$, and in the negative region two overlapping reduction processes can be seen at -0.52 and $-0.72 \mathrm{~V}$ vs $\mathrm{Ag} / \mathrm{AgCl}$. The obtained value of the $1^{\text {st }}$ reduction potential for $\left(\mathrm{SN}_{2}\right) \mathrm{Pyz}(\mathrm{CN})_{2}(2)$ is comparable with such strong $\pi$-electron acceptors as tetracyanoethylene (TCNE), tetracyanoquinodimethane (TCNQ) and its mono- and diannulated 1,2,5-thiadiazole derivatives $\left(\left(\mathrm{SN}_{2}\right) \mathrm{TCNQ}\right.$ and $\left.\left(\mathrm{SN}_{2}\right) \mathrm{TCNQ}\left(\mathrm{N}_{2} \mathrm{~S}\right)\right)\left(\mathrm{E} 1 / 2 \sim 0-+0.2 \mathrm{~V}\right.$ vs SCE in MeCN, ${ }^{25,26}$ Table $1 \mathrm{~S}$ (see Supplementary File). 1,2,5Thiadiazolopyrazine $\left(\left(\mathrm{SN}_{2}\right) \mathrm{Pyz}\right),{ }^{27}$ its dichloro-substituted $\left(\left(\mathrm{SN}_{2}\right) \mathrm{PyzCl}_{2}\right)$ and benzo-fused $\left(\left(\mathrm{SN}_{2}\right) \mathrm{PyzBz}\right)$ derivatives ${ }^{28}$ have much more negative $1^{\text {st }}$ reduction potentials $(-0.83,-0.56,-0.46 \mathrm{~V}$ vs SCE in MeCN, respectively), and only bis(1,2,5-thiadiazolo)pyrazine $\left(\left(\mathrm{SN}_{2}\right) \operatorname{Pyz}\left(\mathrm{N}_{2} \mathrm{~S}\right)\right)$ has the close value of the $1^{\text {st }}$ reduction potential $\left(+0.10 \mathrm{~V}\right.$ vs SCE in $\left.\mathrm{MeCN}^{28}\right)$. Interestingly, 1,2,5-thiadiazolo-3,4-dicarbonitrile $\left(\left(\mathrm{SN}_{2}\right) \mathrm{C}_{2}\left(\mathrm{CN}_{2}\right)\right.$ is reduced only at $-1.07 \mathrm{~V}$ (vs SCE in $\mathrm{MeCN}^{29}$ ), close to that of pyrazine-2,3-dicarbonitrile (Pyz(CN) $2,-1.09 \mathrm{~V}$ vs SCE in pyridine ${ }^{22}$. This indicates that the 1,2,5-thiadiazole fragment and two cyano groups induce a strong positive shift of the first reduction potential only when they are combined with the electron-deficient pyrazine ring. At the same time, all so far known pyrazine-2,3-dicarbonitriles are reduced with more difficulty than $\left(\mathrm{SN}_{2}\right) \mathrm{Pyz}(\mathrm{CN})_{2}$ (2). Thus, the tetracyano derivative $\mathrm{Pyz}(\mathrm{CN})_{4}$ is reduced only at $-0.23 \mathrm{~V}\left(\mathrm{vs} \mathrm{SCE} \mathrm{in} \mathrm{CH}_{2} \mathrm{Cl}_{2}{ }^{30}\right)$, albeit more easily that other 5,6-substituted derivatives $\mathrm{R}_{2} \mathrm{Pyz}(\mathrm{CN})_{2}\left(\mathrm{R}=\mathrm{Ph}, 2-\mathrm{Py}, 2-\mathrm{Py}{ }^{+} \mathrm{Me}\right){ }^{22}$ Fusion of additional pyrazine fragments in $\mathrm{R}_{2} \mathrm{Pyz} P y z(\mathrm{CN})_{2}$ increases electron-deficiency, but the reduction potentials are shifted

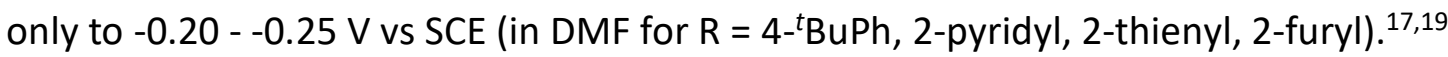




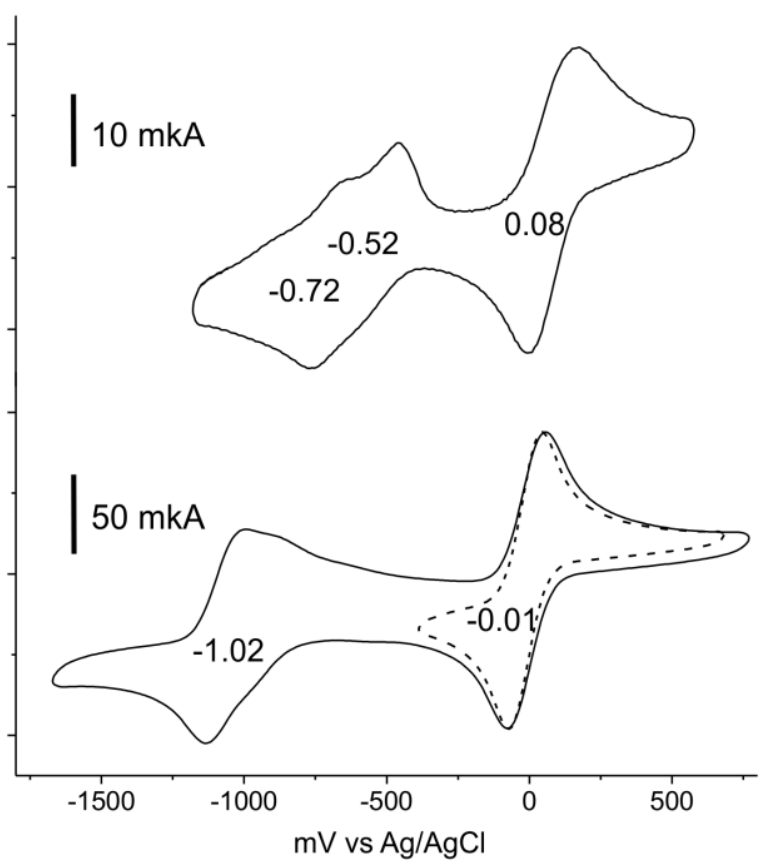

Figure 3. CVA of 1,2,5-thiadiazolo[3,4-b]pyrazine-5,6-dicarbonitrile (2) in MeCN (bottom) and in DMSO(top). Supporting electrolyte $0.1 \mathrm{M} \mathrm{tbaClO}_{4}$, scan rate $100 \mathrm{mV} / \mathrm{s}$, reference $\mathrm{Ag} / \mathrm{AgCl}$.

\section{Porphyrazine complexes}

The dinitrile 2 was used as precursor for preparation of tetrapyrazinoporphyrazines with fused 1,2,5-thiadiazole rings, [T(SN 2 Pyz)PAM]. Already upon melting at $232{ }^{\circ} \mathrm{C}$ the dinitrile 2 turns greenish-brown due to selfmacrocyclization process. Template Linstead cyclotetramerization of $\mathbf{2}$ in the presence of $\mathrm{Mg}^{\prime \prime}$ butoxide in $n$ butanol under reflux affords the $\mathrm{Mg}$ (II) complex 3 only with $11 \%$ yield. Such low yield might be connected with participation of this strongly electron-deficient dinitrile in side reactions, e.g. in nucleophilic substitution of CN groups by butoxide as a strong nucleophile. Cyclotetramerization of the dinitrile $\mathbf{2}$ in non-nucleophilic conditions in the presence of In(III) chloride in 1,2,4-trichlorobenzene leads to the In(III) complex 4 with $28 \%$ yield. The obtained complexes [T(SN $\left.\left.\mathrm{SNyz}_{2} \mathrm{PAM}\right], \mathrm{M}=\mathrm{Mg}(3), \ln (\mathrm{Cl})(4)\right)$ are practically insoluble in non-donor organic solvents and can be purified from organic impurities by extraction. The solubility in donor solvents (pyridine, DMSO) is higher and the obtained complexes were additionally reprecipitated from DMSO solutions.

The MALDI mass-spectra could be obtained only for the $\ln (\mathrm{III})$ complex 4 (Figure 4). In the negative region the molecular ion peak $[4-\mathrm{Cl}+\mathrm{H}]^{-}$is observed at $868 \mathrm{Da}$. In the positive region the peak is observed at $\mathrm{m} / \mathrm{z} 783$ $\mathrm{Da}$. It might be very likely assigned to a defragmentation product with the loss of four $\mathrm{S}$ atoms and formation of positively charged ion of octaimino derivative $[4-4 \mathrm{~S}+9 \mathrm{H}]^{+}$. Interestingly, this peak has the isotopic distribution typical for the presence of chlorine atom, indicating that the $\mathrm{In}^{\text {III }}$ complex 4 contains $\mathrm{Cl}$ as axial ligand which is retained in this positively charged ion.

Low solubility and/or strong tendency of porphyrazines $\mathbf{3}$ and $\mathbf{4}$ to aggregation prevent using NMR spectroscopy for their characterization. 


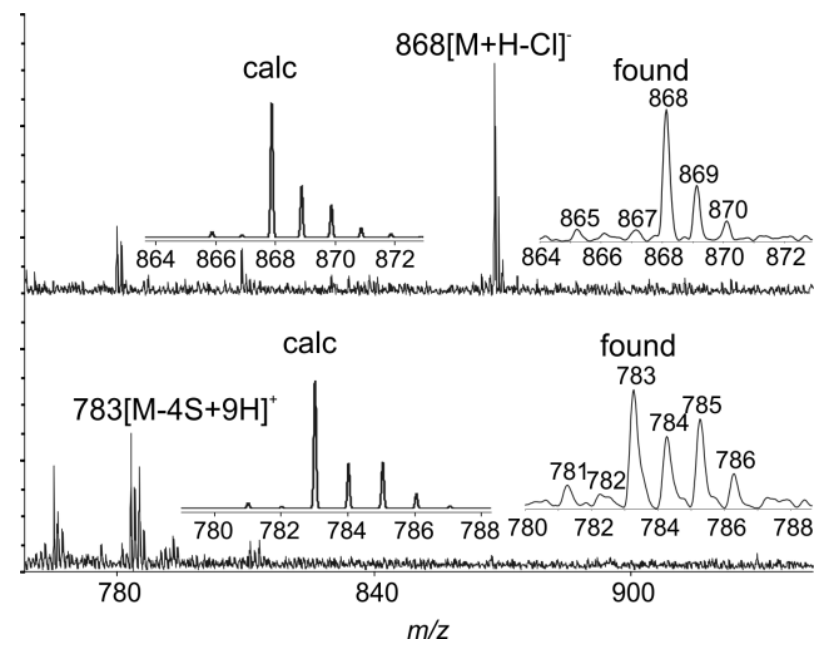

Figure 4. MALDI mass-spectra (CHCA matrix) of the In ${ }^{\prime \prime \prime}$ complex 4 in the negative (top) and positive (bottom) regions. Inserts display the experimental and theoretical isotopic distribution patterns.

Freshly prepared solutions of complexes $\mathbf{3}$ and $\mathbf{4}$ in donor solvents (DMSO, pyridine) contain strongly broadened absorption bands in the visible region $(600-700 \mathrm{~nm})$ due to considerable aggregation effects. On prolonged staying the spectra of the diluted solutions become typical for non-aggregated porphyrazine complexes (Figure 5) and exhibit a single $Q$ band in the visible region near $660 \mathrm{~nm}$ and more intense and broad Soret band in the UV-region (370 nm for 3 and $369 \mathrm{~nm}$ for 4). The Q-band maxima are shifted bathochromically by $15-25 \mathrm{~nm}$ as compared to the corresponding complexes of unsubstituted tetrapyrazinoporphyrazine [TPyzPAM] $(\mathrm{M}=\mathrm{Mg}(\mathrm{II}), \mathrm{In}(\mathrm{III}) \mathrm{Cl})^{8}$ due to enlargement of the $\pi$-chromophore by annulation of 1,2,5-thiadiazole rings. At the same time the maximum of the Q-band is shifted hypsochromically to $\sim 660 \mathrm{~nm}$ as compared to complexes of the TPyzPA macrocycles with fused less electrondeficient heterocyclic fragments, e.g. pyrazine $(700-720 \mathrm{~nm}),{ }^{17,19}$ isoindole $(\sim 715 \mathrm{~nm})^{13}$ or thianaphthene $(\sim 690 \mathrm{~nm}) .{ }^{14}$

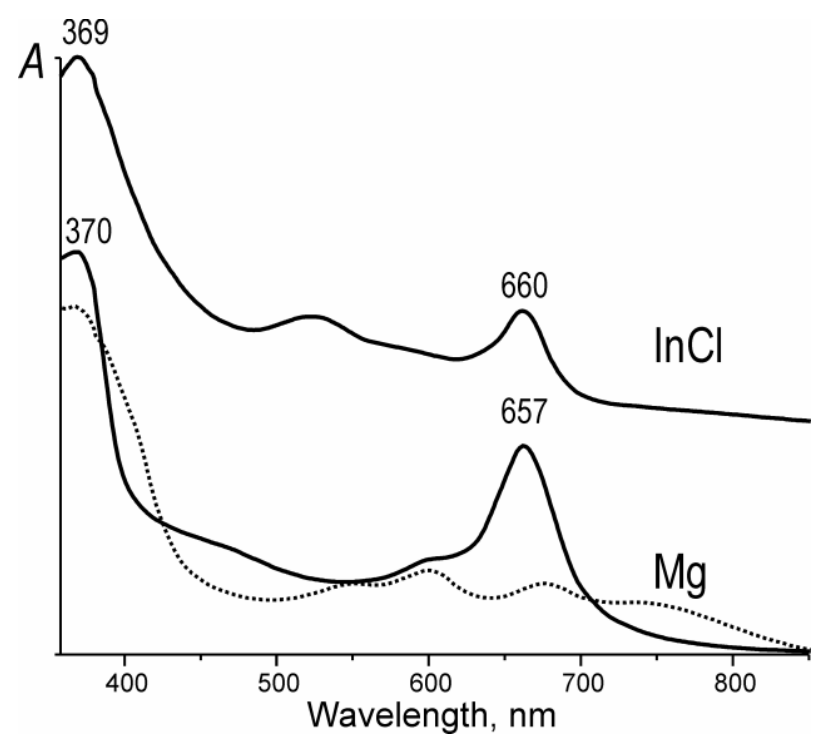

Figure 5. UV-VIS spectra of the $\mathrm{Mg}(\mathrm{II})$ and $\ln (\mathrm{III})$ complexes (3 and $\mathbf{4}$ ) in DMSO. Dotted line shows the spectrum of aggregated species in freshly prepared solution. 
The electrochemical study using cyclic voltammetry confirms that fusion of 1,2,5-thiadiazole rings increases the electron-deficient properties of the TPyzPA macrocycle. For the $\mathrm{Mg}(\mathrm{II})$ complex 3 three reduction waves are observed at $-0.38,-0.83$ and $-1.21 \mathrm{~V} v \mathrm{Ag} / \mathrm{AgCl}$ in DMSO (Figure 6). The $1^{\text {st }}$ reduction potential is shifted more positively by $200-300 \mathrm{mV}$ as compared to benzo and by $\sim 100 \mathrm{mV}$ as compared to pyrazine fused TPyzPA (for $\mathrm{Zn}$ (II) complexes of tert-butylsulfanyl substituted TPyzPA with four fused benzene and pyrazine rings $\mathrm{E}_{1 / 2}=-0.66$ and $-0.49 \mathrm{~V}$ vs SCE in THF, respectively $\left.{ }^{18}\right)$.

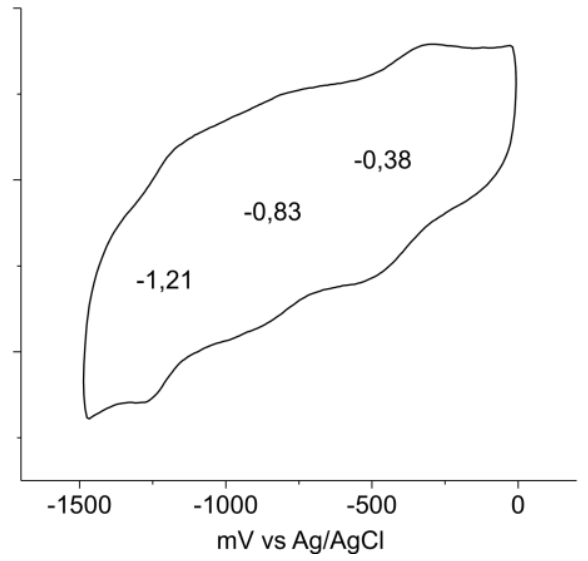

Figure 6. CVA of the $\mathrm{Mg}(\mathrm{II})$ complex 3 in DMSO. Supporting electrolyte $0.1 \mathrm{M}$ tbaClO 4 , scan rate $100 \mathrm{mV} / \mathrm{s}$, reference $\mathrm{Ag} / \mathrm{AgCl}$.

\section{Conclusions}

1,2,5-Thiadiazolo[3,4- $b$ ]pyrazine-5,6-dicarbonitrile which can be obtained by treatment of 5,6-diaminopyrazine-2,3-dicarbonitrile with $\mathrm{SOCl}_{2}$ under reflux exhibit very strong electron-deficient properties and can be used as precursor in the template synthesis of macrocyclic complexes of tetrapyrazinoporphyrazines with fused 1,2,5-thiadiazole rings.

\section{Experimental Section}

General. The IR spectra were measured on an IR-spectrometer AVATAR 360 FT-IR using KBr pellets. UV-vis spectra were recorded using a Hitachi U-2000 spectrophotometer. Mass-spectrometric measurements were carried out on a MALDI-TOF Shimadzu Biotech Axima Confidence spectrometer in negative and positive modes. Elemental analyses were performed on a CHN analyser Flash EA 1112.

Reduction potentials were measured in deoxygenated (Ar) dimethylsulfoxide (Aldrich) solution containing 0.1 $M$ tetrabutylammonium perchlorate as supporting electrolyte on a potentiostat Elins P-4 equipped with a three electrode electrochemical cell with a glassy carbon working electrode, a Pt wire counter electrode and an $\mathrm{Ag} / \mathrm{AgCl}$ reference electrode. The reference $\mathrm{Fc} / \mathrm{Fc}+$ couple was observed at $+0.465 \mathrm{~V} \mathrm{vs} \mathrm{Ag} / \mathrm{AgCl}$. The obtained potential values are negatively shifted versus Standard Calomel Electrode (SCE) by $0.035 \mathrm{~V}$ (the recommended value of the $\mathrm{Fc} / \mathrm{Fc}+$ correction vs SCE in DMSO is $+0.50 \mathrm{~V}^{31}$ ).

1,2,5-Thiadiazolo[3,4-b]pyrazine-5,6-dicarbonitrile, $\left(\mathrm{SN}_{2}\right) \mathrm{Pyz}(\mathrm{CN})_{2}$ (2), was prepared closely following the procedure suggested by Tong. ${ }^{21}$ 2,3-Diaminopyrazine-5,6-dicarbonitrile ( $2 \mathrm{~g}, 12.5 \mathrm{mmol}$, TCl Europe) was suspended in $p$-xylene $(100 \mathrm{ml})$ and after addition of thionyl chloride $(4 \mathrm{ml})$ the mixture was refluxed for $20 \mathrm{~h}$. 
After evaporation of the solvent under reduced pressure the dark-brown residue was sublimed in vacuum (10 Torr) to give a yellow product $(1.2 \mathrm{~g}, 51 \%)$. m. p. $232{ }^{\circ} \mathrm{C}$ (decomp.) Selected IR $(\mathrm{KBr}), v_{\max }\left(\mathrm{cm}^{-1}\right): 2235(\mathrm{w})$ $(v(C N), 1628(w), 1524(w), 1365(m), 1302(m), 1251(v s), 1124(m), 902(s), 837(w), 567(s), 510(m), 432(m)$, 404(m). ${ }^{13} \mathrm{C}$ NMR (50.32 MHz, CD $\left.{ }_{3} \mathrm{CN}\right): \delta$ 114.28, 134.13, 154.30. MS (MALDI-TOF, negative) (m/z, negative): 188 (100\%) [M]-, 156 (95\%) [M - S] $]^{-}$. Calc. for $\mathrm{C}_{6} \mathrm{~N}_{6} \mathrm{~S}$ (188.17): C, 38.30; N, 44.66; S, 17.04. Found: C, 38.50; N, $44.20 ;$ S, $16.20 \%$.

Tetrakis(1,2,5-thiadiazolo[3,4:5,6]pyrazino)porphyrazinatomagnesium(II) (3). [T(SN2Pyz)PA]Mg. Dinitrile 2 (200 mg, $1.06 \mathrm{mmol}$ ) was added to solution of magnesium $(26 \mathrm{mg})$ in $n$-butanol $(25 \mathrm{ml})$ and the reaction mixture was heated under reflux for $6 \mathrm{~h}$. After evaporation of the solvent the residue was washed with $20 \%$ aqueous acetic acid, centrifuged and washed with water and acetone. The solid residue was dissolved in DMSO, filtered and precipitated by pouring in water, washed and dried to give the $\mathrm{Mg}$ (II) complex 3 (24 mg, 11\%). Calc. for $\mathrm{C}_{24} \mathrm{MgN}_{24} \mathrm{~S}_{4} \cdot 4 \mathrm{H}_{2} \mathrm{O}$ (849.03): C, 33.95; $\mathrm{H}, 0.95 ; \mathrm{N}, 39.59 ; \mathrm{S}, 15.10 \%$. Found: $\mathrm{C}, 33.50 ; \mathrm{H}, 0.97 ; \mathrm{N}$, 38.65; S, 14.46\%. Selected IR $\left(\mathrm{KBr}, \mathrm{cm}^{-1}\right): 1624(\mathrm{~s}), 1464(\mathrm{~s}), 1387(\mathrm{~m}), 1322(\mathrm{~m}), 1226(\mathrm{~m}), 1120(\mathrm{~s}), 1055(\mathrm{w})$, 724(s).

Tetrakis(1,2,5-thiadiazolo[3,4:5,6]pyrazino)porphyrazinatoindium(III) chloride (4). [T(SN $\left.\left.{ }_{2} \mathrm{Pyz}\right) \mathrm{PA}\right] \mathrm{InCl}$. Dinitrile $2(200 \mathrm{mg}, 1.06 \mathrm{mmol})$ and indium(III) chloride trihydrate $(73 \mathrm{mg}, 0.27 \mathrm{mmol}$ ) were heated to reflux in 1,2,4trichlorobenzene for $1 \mathrm{~h}$. The reaction mixture was diluted with acetone $(50 \mathrm{ml})$ and centrifuged. The solid residue was dissolved in DMSO, filtered and precipitated by pouring in water, washed and dried to give the In(III) complex (68 mg, 28\%). MS (MALDI-TOF, matrix - CHCA) ( $\mathrm{m} / \mathrm{z}$, negative): 868.1 Da (calculated for $\left.\mathrm{C}_{24} \operatorname{lnN}_{24} \mathrm{ClS}_{4}-901.83 \mathrm{Da},[\mathrm{M}-\mathrm{Cl}+\mathrm{H}]^{-}-867.9 \mathrm{Da}\right)$. Calc. for $\mathrm{C}_{24} \mathrm{ClInN}_{24} \mathrm{~S}_{4} \cdot 3 \mathrm{H}_{2} \mathrm{O}$ (956.98): C, 30.12; $\mathrm{H}, 0.63 ; \mathrm{N}$, 35.13; S, 13.40\%. Found: C, 30.44; H, 0.64; N, 34.68; S, 11.82\%. Selected IR $\left(\mathrm{KBr}, \mathrm{cm}^{-1}\right): 1630(\mathrm{~m}), 1470(\mathrm{~s})$, $1310(\mathrm{~m}), 1130(\mathrm{~s}), 1030(\mathrm{~m}), 700(\mathrm{~m}), 557(\mathrm{w})$.

\section{Acknowledgements}

We are grateful for financial support to Russian Foundation of Basic Research (grants 13-03-0902a and 16-0301048a, synthesis and physico-chemical characterization) and Russian Science Foundation (grant 14-23-00204, quantum-chemical calculations). IR and mass-spectra measurements and elemental analysis were performed in the Collective Usage Center of Ivanovo State University of Chemical Technology.

\section{References}

1. Stuzhin, P. A., Ercolani C. In The Porphyrin Handbook; Kadish, K. M.; Smith, K. M.; Guilard, R. Eds.; Academic Press: Amsterdam, 2003; Vol. 15, pp 263-364.

https://doi.org/10.1016/B978-0-08-092389-5.50011-0

2. Donzello, M.P.; Ercolani, C.; Stuzhin P. A. Coord. Chem. Rev. 2006, 250, 1530-1561.

https://doi.org/10.1016/j.ccr.2006.02.009

3. Stuzhin, P. A.; Mikhailov, M. S.; Yurina, E. S.; Bazanov, M. I.; Koifman, O. I.; Pakhomov, G. L.; Travkin, V. V.; Sinelshchikova, A. A. Chem. Comm. 2012, 10135 - 10137.

https://doi.org/10.1039/c2cc35580a 
4. Miyoshi, Y.; Kubo, M.; Fujinawa, T.; Suzuki, Y.; Yoshikawa, H.; Awaga, K. Angew. Chem. Int. Ed. 2007, 46, $5532-5536$.

https://doi.org/10.1002/anie.200700702

5. Miyoshi, Y.; Fujimoto, T.; Yoshikawa, H.; Matsushita, M. M.; Awaga, K.; Yamada, T.; Ito, H. Organic Electronics 2011, 12, 239-243.

https://doi.org/10.1016/j.orgel.2010.11.005

6. Stuzhin, P. A.; Mikhailov, M. S.; Travkin, V. V.; Gudkov, E. Y.; Pakhomov, G. L. Macroheterocycles 2012, 5, 162-165.

https://doi.org/10.6060/mhc2012.120573p

7. Stuzhin, P.A.; Mikhailov, M. S.; Travkin, V. V.; Pakhomov, G. L. In: Recent Developments in Coordination, Bioinorganic, and Applied Inorganic Chemistry. Melnik, M.; Segl'a, P.; Tatarko, M. (Edrs). Bratislava, Press of Slovak University of Technology, 2013. Volume 11, 318-323.

https://doi.org/10.13140/2.1.2341.3761

8. Donzello, M. P., Ercolani, C.; Novakova, V.; Zimcik, P.; Stuzhin, P. A. Coord. Chem. Rev. 2016, 309, 107179; and references cited therein.

http://dx.doi.org/10.1016/j.ccr.2015.09.006

9. Schlettwein, D.; Woehrle, D.; Karmann E.; Melville, U. Chemistry of Materials 1994, 6, 3-6. http://dx.doi.org/10.1021/cm00037a001

10. Hamdoush, M.; Ivanova, S. S.; Koifman, O. I., Kos'kina, M.; Pakhomov, G. L.; Stuzhin, P. A. Inorg. Chim. Acta 2016, 444, 81-86.

https://doi.org/10.1016/j.ica.2016.01.029

11. Donzello, M. P.; Viola, E.; Cai, X.; Mannina, L.; Rizzoli, C.; Ricciardi, G.; Ercolani, C.; Kadish, K. M.; Rosa, A. Inorg. Chem. 2008, 47, 3903; and references cited therein.

https://doi.org/10.1021/ic702430j

12. Jaung, J.-Y.; Matsuoka, M.; Fukunishi, K. J. Chem. Res.1998, 284-285; (M) 1301-1323. https://doi.org/10.1039/a708049b

13. Jaung, J.-Y; Matsuoka, M.; Fukunishi, K. Synthesis 1998, 1347-1351. https://doi.org/10.1055/s-1998-6092

14. Taraymovich, E. S.; Enakieva, Y. Y.; Mitasova, Y. V.; Stuzhin, P. A. Macroheterocycles 2010, 3, 48-50. https://doi.org/10.6060/mhc2010.1.48

15. Taraimovich, E. S.; Stuzhin, P. A.; Koifman, O. I. Russ. J. Gen. Chem. 2013, 83, 392-397. https://doi.org/10.1134/S1070363213020266

16. Novakova, V.; Roh, J.; Gela, P.; Kuneš, J.; Zimcik, P. Chem. Commun. 2012, 48, 4326. https://doi.org/10.1039/c2cc30942d

17. Song, C. J.; Jang, C. K.; Yao, W.; Jaung, J. Y. J. Chem. Res. 2013, 37, 268.

https://doi.org/10.3184/174751913X13642346476213

18. Novakova, V.; Reimerova, P.; Svec, J.; Suchan, D.; Miletin, M.; Rhoda, H.; Nemykin, V. N.; Zimcik, P. Dalton Trans. 2015, 44, 13220-13233. https://doi.org/10.1039/C5DT01863C

19. Novakova, V.; Małachwiej, B.; Šebl, R.; Miletin, M.; Zimcik, P. J. Porphyrins Phthalocyanines $2017,21$. https://doi.org/10.1142/S1088424617500146

20. Svec, J.; Zimcik, P.; Novakova, L.; Rakitin, O. A.; Amelichev, S.; Stuzhin, P. A.; Novakova, V. Eur. J. Org. Chem. 2015, 596-604. 
21. Tong, Y. U. S. patent 3850929 A. 1974. http://www.google.by/patents/US3850929

22. Cai, X.; Donzello, M. P.; Viola, E.; Rizzoli, C.; Ercolani, C.; Kadish, K. M. Inorg. Chem. 2009, 48, 7086-7098. https://doi.org/10.1021/ic8023277

23. Li, X.; Donzello, De Mori, G.; Viola, E.; Futur, D.; Fu, Z.; Rizzoli, C.; Mannina,L.; Bodo, E.; Astolfi, M. L.; Ercolani, C.; Kadish, K. M. Eur. J. Inorg. Chem. 2014, 3572-3581. https://doi.org/10.1002/ejic.201402282

24. Yamaguchi, S.; Tatemitsu, H.; Sakata, Y.; Misumi, S. Chem Lett, 1983, 1229-1230. https://doi.org/10.1246/cl.1983.1229

25. Suzuki, T.; Yamashita, Y.; Fukushima, T.; Miyashi, T. Mol. Cryst. Liq. Cryst. 1997, 296, 165-180. https://doi.org/10.1080/10587259708032319

26. Suzuki, T.; Fujii, H.; Yamashita, Y.; Kabuto, C.; Tanaka, S.; Harasawa, M.; Mukai, T.; Miyashi, T. J. Am. Chem. Soc. 1992, 114, 3034-3043. https://doi.org/10.1021/ja00034a041

27. Semenov, N. A.; Pushkarevsky, N. A.; Suturina, E. A.; Chulanova, E. A.; Kuratieva, N. V.; Bogomyakov, A. S.; Irtegova, I. G.; Vasilieva, N. V.; Konstantinova, L. S.; Gritsan, N. P.; Rakitin, O. A.; Ovcharenko, V. I.; Konchenko, S. N.; Zibarev, A. V. Inorg. Chem. 2013, 52, 6654-6663.

https://doi.org/10.1021/ic400659q

28. Yamashita, Y.; Saito, K.; Suzuki, T.; Kabuto, C.; Mukai, T.; Miyashi, T. Angew. Chem. Int. Ed. 1988, $27,434$. https://doi.org/10.1002/anie.198804341

29. Suturina, E. A.; Semenov, N. A.; Lonchakov, A. V.; Bagryanskaya, I. Y.; Gatilov, Y. V.; Irtegova, I. G.; Vasilieva, N. V.; Lork, E.; Mews, R.; Gritsan, N. P.; Zibarev, A. V. J. Phys. Chem. A 2011, 115, 4851-4860. https://doi.org/10.1021/jp2019523

30. Malini, R.; Krishnan, V. Bull. Soc. Chim. Belges 1980, 89, 359-369. https://doi.org/10.1002/bscb.19800890506

31. Lever, A. B. P.; Milaeva, E. R.; Speier, G. The Redox Chemistry of Metallophthalocyanines in Solution; in Phthalocyanines: Properties and Applications, Leznoff, C.C.; Lever, A.B.P., Eds.; New York: VCH Publishers, Inc. 1993; vol. 3, pp: 1-70. 